\title{
Making Nature, Making Energy, Making humans: two exhibitions at the Wellcome Trust
}

Angela Last, University of Warwick

The Wellcome Collection currently has two exhibitions on show: "Making Nature: How we see animals" and "Electricity: The spark of life". Despite their seemingly disparate topics - one exhibition speaks about our co-existence with animals, the other about energy futures - they speak to each other in quite thought-provoking, and perhaps suitably Anthropocenic ways: how are we human in these times, and what possible trajectories are available to us? The proposal of the Anthropocene - a geologic epoch in which humans constitute a geophysical force and leave distinctive geologic traces - has prompted a multitude of attempts at human self-definition that reconsider our co-existence with and co-constitution through the 'nonhuman'. Yet the Anthropocene is just the latest framing of a human identity in a long-term challenge of nature-culture boundaries, exemplified by proposals such as Donna Haraway's 1984 (1991) Cyborg Manifesto or Edouard Glissant's 'La Lézarde' (1958). As in Haraway's manifesto, which takes as a starting point the increasing breakdown of the human/animal, human/machine and physical/non-physical separations, the exhibitions try to unsettle boundaries which continue to shape the European and Euro-centric self-imagination.

\section{Making Nature: An exhibition of boundary work in progress}

The first installation in the corridor leading towards the Making Nature exhibition rather successfully sets the tone for the exhibition. Marcus Coates and Volker Sommer's provocative (and amusing) Degreecoordinates. Shared Traits of the Hominini Apes (Humans, Bonobos and Chimpanzees) confronts you with an entire wall of questions such as "Do you express rage? Do you have sex with more than one partner? Can you imitate others? Do you eat pigs? Do you grieve?" These questions emphasise that there may be fewer differences between species than between individuals within a species. It really asks: what makes us humans and them animals? This line of questioning continues throughout the different subthemes of Ordering, Displaying, Observing and Making.

Ordering opens with Allora \& Calzadilla and Ted Chiang's powerful film triptych The Great Silence. Contrasting human efforts to search for extraterrestrial intelligence with human disregard or even annihilation of earthly 'resident aliens' such as parrots, the piece asks why we do not consider nonhuman intelligence around us enough, especially where there are existing bridges in communication such as vocalisation. How are we going to engage with even more alien species if we already fail with the aliens at home? The remainder of the Ordering section continues with the human (especially Western humanity's) struggle with sense-making. Citations from Linnaeus to Borges not only show how different worldviews have shaped classification, but also hint at their agendas of making particular delineations. As Linnaeus points out the power of naming, Borges stresses its frequent arbitrariness: 
nothing is given and so becomes subject to very human forces. This is true for objects that seem to defy classification, as well as for objects where classification seems very straightforward. At the end of this room, one is not far away from asking oneself how clueless humanity is at this point in time: in how many years will people laugh at our current ways of ordering? Another question that surfaces could be phrased as: how much is our degrading of the environment a consequence of our current classifications?

This section alone would have been enough satisfaction in terms of the question it raises, however, the exhibition continues with Displaying. My favourite exhibits in this section are the photographs of taxidermied museum animals in storage. Seeing these animals partially covered in paper or plastic wraps, or arranged into a surreal display cabinet army of its kind, made for some deeply embarrassing 'my species is weird' moments. The other exhibits prove even mortifying in this respect, with examples of indulgently anthropomorphic arrangements such as card playing squirrels. This room partly reminds me of the 'Crappy Taxidermy' web archive and related ebay auctions, and partly of Tahani Nadim and Åsa Sonjasdotter's 2015 Dead wasps fly further exhibition and performance at the Natural History Museum in Berlin. The latter included a tour around the museum's storage and research rooms, during with Nadim progressively transformed into an insect and read from different historical classification struggles around the species she embodied. Displaying, too, featured a human-insect performance in the form of Edwina Ashton's Moth (2002), in which she contrasts attempts at classification with "the idiosyncratic behaviour of the giant insect on screen". Like Nadim's tour through the bizarre excesses of natural history research, the excess of the exhibits in the room and the further excesses they hinted at (mass hunting, collectors' obsession, desire for sensationalism, intensive labour behind the scences etc) became another question mark, perhaps best summed up as: why do we do this? Why do we feel the need to order everything around us and even drive species to extinction in order to do this?

The obvious traffic between science and entertainment highlights further issues. Whether it is exhibiting 'freak' humans or bizarre animal scenarios, there is something disturbing in the popularity of such consumption: where does education end and perversion begin? The recent debates around zoos or 'ethnological' collections exemplify this tension. Is it still defensible to hold animals in captivity for entertainment or educational purposes? It is still defensible to display objects, taken under colonialism and frequently belonging to intimate spheres of other cultures? Some comic relief was provided in the form of the Crystal Palace dinosaur exhibits that never fail to puzzle but also illustrate the incredible desire to know and display this knowledge, in this case knowledge of the past. In fact, this desire feels deeply connected to the desire to not only understand but to shape. How much do we shape through mere 'knowing'? What difference does it make in how we portray dinosaurs, for instance?

The next room proceeds to show how Observing is not merely a hands-off act. Again, not only are our observations dependent on the settings we create (e.g. caged or free 
roaming animals), but also on how we pass on our observations (e.g. through different types of presentations, films, books). This section included troubling examples from the history conservation areas, such as the transition from hunting grounds to zoos to doomsday vaults, or the 'invention' of wilderness and its reflection in more or less eccentric wildlife documentaries. A central position was given to the two-screen installation Ming of Harlem: Twenty One Storeys in the Air by Phillip Warnell (2016). Based on the real life of Antoine Yates, it shows how he lived with a tiger called Ming and an alligator in a New York high-rise apartment. While one screen just focuses on the animals and their everyday life, the second screen shows Yates' reflections of living with them, as well as some footage from the life in the rest of the building. It is great to have a contrast between the intentionally designed spaces and wildernesses with this apparently random everyday setting in which wild animals were never meant to be. As much as these spaces contrast, however, they do put each other in question: is a zoo any more appropriate than an urban high rise? Why can't we live with animals other than a few designated and elaborately modified 'pets'? And who makes such decisions?

Another pertinent image that this section elicits is the transfixion of audiences behind a multitude screens and the abysmal conditions of many of the species they are observing. This apparent disconnect also seems to take place without the presence of screens, for instance, in the extravagant spaces of zoological gardens. Watching the elaborate design processes as well as the elaborate grooming and selfdisplaying of the visitors in these supposedly animal-focused spaces raised the question of what we need the 'other animals' for in these spaces anyway? Can humans not just parade around and announce their superior status without animals having to serve ornamental functions? Why make such an effort at creating spectacular artificial habitats?

The last room in the exhibit, Making, finally confirms how knowing, observing, classifying, displaying and even being is a process of co-authoring. Focusing on the work of the Center for PostNatural History, the displays show how animals and plants have been altered through human domestication, experimentation, accidents, economy, breeding and even resurrection efforts. Whether it is racing animals, singing birds, transgenic mosquitos, lab rats, Chernobyl leaves or spider silk producing goats, humans have started to give evolution a hand - or a spin at least. Despite its heavy focus on genetics, it was emphasises that drastic shifts did not have to occur at the level of physical make-up. To read that even the songs of animals could be manipulated to suit human tastes was fascinating. How 'natural' are the animal sounds we hear around us? Where does this modification begin and end?

The other question the Making section implicitly poses is: how much are humans being shaped by their environment? Why there were no concrete examples of plant, cat or fungi overlords, examples such as radiation or domestication hinted at the power of the nonhuman to affect us back. Whether it is through diseases, accidental exposure or nonhumans' desires to proliferate, it seems likely that we are what we 
are through co-evolution with other species. Here, the exhibition really came fullcircle: after all, humans, too, are essentially nonhuman. Humanity is a boundary that carefully needs to be established through continuous work, since this boundary is constantly being put in question.

Overall, the exhibition felt like an accessible romp through the last few decades of science studies. Complex debates around the postnatural, companion species and the politics of display were broken down and even made entertaining through key examples, but also creative juxtaposition. What really worked was the destabilisation of boundaries between the human and the nonhuman, which was remarkably kept up through the four rooms. Although the last room could have done with more examples of nonhuman ways of making the human, the preceding stabilisations may have been sufficient to doubt the 'human as maker' story. In fact, one gains the impression that, in a few decades, some parrot visitors to a future exhibit are going to smile at this human effort at marking itself out as special.

\section{Electricity: the making of supernatural futures}

The co-evolution with the nonhuman theme is continued in the floor below with an even bigger exhibition on Electricity. Again, the displays see humans struggle with something both familiar and alien: while humans pretty much exist due to electricity (brains!), this form of energy remained a mystery to them for a very long time. Only due to experiments with a variety of animate and inanimate materials did humans start to get a sense of what this elusive force was about. In fact, the word 'electron', as one learns at the beginning of the exhibition, came from studying the light inducing properties of amber, with 'electron' meaning 'formed by the sun'. This parallel process of sense-making, in addition to studying animals for theories of evolution, was again vividly illustrated through a mixture of factual and artistic exhibits.

Electricity: The spark of life is structured by the three themes of Generation, Supply and Consumption. Generation started by reminding visitors of early encounters with electricity, through phenomena such as bioelectricity (e.g. in fish), lightning or aurora borealis. This section gives a good sense of how much early experiments with electricity constituted a shift in worldview and its related hierarchies of human and divine. Many of the experiments to capture, direct or use electricity maintain an echo of this association with the supernatural, whether in eery early photography, reanimation attempts or 'playing God' with the (Edison-designed) electric chair and other means of taking lives (drones come to mind). How much does our relationship with electricity still influence a human self-image of mastery? How much does this relationship shape how we make divisions between humans?

As in the Making Nature exhibition, the other close relation is between science and entertainment. From extravagant therapies to suspended humans and frogs, showmanship seems to shape trajectories of engagement with the 'spark of being'. In contrast with the freak human and animal mutations in Making Nature, however, 
the emphasis is less on making sense of difference in the present than on imagining different futures for humanity. Although animals again figured as central means in this search, they appear more strongly as conduits. Generation concluded with an artwork that emphasised the role of animals in humanity's search for a 'next step'. Making a connection between past frog experiments that centred around reanimation and present experiments that focus on human survival beyond Earth, John Gerrard's X.laevis (Spacelab) transmitts a sense of this suspension between present and future - our actually quite clumsy attempts at presencing the unknown.

The next section, Supply, gives a more practical dimension to making the unknown present. It deals with all the logistics and system options that were considered in bringing electricity to where it was presumed to be needed. At first, hardly anyone could imagine electricity and even less so for what it could be used. The public had to be won over through campaigns to appreciate its utility and safety. At the same time, a 'war of currents' was fought over alternating (AC) versus direct (DC) current, represented by Nikola Tesla and Thomas Edison respectively. Unlike the film The Prestige that deals with this 'war', Electricity stages this rivalry very subtly, focusing more on the practicalities rather than inventor personalities, despite Faraday, Ferranti and others being featured with their respective contributions. Instead, it is projects such as the Deptford power station and the transatlantic telegraph cable that take centre stage, with all their tedious logistical issues: how do we lay a cable between Europe and America safely on the ocean floor? Where do we place a power plant so that it can be fuelled and also be close to people? And if it is close to people, how will we protect them from electrocution? And how do we connect things up into a National Grid? How do deal with extreme weather events and natural disasters, such as the 1888 New York blizzard that wreaked havoc on overhead cables?

The social aspect of electricity supply is also addressed. Now that cities could be illuminated at night, a whole new dimension of nightlife could be imagined. Walter Ruttman's Berlin: Symphony of a great city (1927) showcased the new popularity of cinemas, concerts, trams, and even ice rinks. World exhibitions now featured the wonders of electrical engineering, and electricity was even given its own fair, the Paris-based International Exposition of Electricity in 1881. This section ends with a film by Bill Morrison (with music by Bill Frisell) who worked with archived films from the Manchester Museum of Science and Industry. Morrison creates something that initially looks like a technical explanation or safety video, but then zooms out to cosmic profundity: what is the future of this planet full of emerging matter-energy beings?

Consumption finally zooms in more closely on the social shifts that occurred through widespread electrification. Naming electricity 'the silent servant', the section appears to hint at both the service that electricity is providing, as well as the many human and animal services that were made redundant as a consequence. Obvious benefits of electricity included greater safety for workers (e.g. miners), less risk from candle/gas fumes in houses and public spaces, better health diagnoses (cine- 
radiography!), and a greater democratisation of access to 'services'. This encompassed mundane household aids such as kettles, which were initially only available to the wealthy. The displays also included anxiety-dispelling electric household guides for sceptical housewives, littered with euphemisms such as 'electric fairies'. At the other end of the spectrum, (literally) hair-raising electric beauty treatments seemed to have caused less consternation. One of my favourite exhibits in this section was a set of tea towels designed by the Electrical Association for Women (EAW), a group that had emerged out of the Women's Engineering Society. EAW members believed in the contribution that electricity could make to the emancipation of women by liberating them from household chores. The tea towels, aprons and dusters produced by the EAW communicate through diagrams and simple instructions to encourage other women to take control of their lives through household based electrical possibilities. The potential downside of electricity seems mostly put in terms of excess, rather than other social issues such as loss or transformation of labour, skills and social patterns: where are we going to get all these energy from on which we have become dependent? Also, given the still unequal access to electricity and its related mechanisation and ueberisation, one could ask: who is being liberated and who profits - or can such a clear cut be made at all?

Consumption seeks to complete this exhibition by looking towards the future and the possibilities that are currently being explored. Camille Henrot's installation 'January 2017 Horoscope' offers a somewhat pessimistic take by apparently channelling a condensed history of electricity through the everyday drag of energy consumption (bills, bills, bills) and the accompaniying sensory excess (strobe light, fire, noise etc). The installation appears to hint at the fact that humanity may become consumed by its addiction to electricity, while electricity itself has the capacity to carry on relentlessly by itself. The exhibits that follow focus on the possibilities of alternative power sources to generate electricity, such as hydro, wind and solar electricity, and their application especially in newly designed urban spaces such as 'sustainable cities'. The exhibition concludes on a panel discussion on the future of electricity, which discusses especially decentralised options such as generating electricity at home and sharing it across peer-to-peer networks. In a way, the exhibition comes full circle with the theme of harnessing cosmic energies: our energy future seems to continue to be 'formed by the sun'.

Like Making Nature, the Electricity exhibition makes great use of a mix of poetic (artwork) and factual objects. Although it presents quite a standard history of electricity, with all the key moments, themes and personas, it manages to give it a poetic dimension, which is not exclusively due to the artwork. There is a real sense of dialogue between the different scientific and cultural objects that seem to prompt the visitor to experiment with positioning our current energy situation within the history that is presented - where are we in our joint journey with electricity? How much do we still have a hangover from 'dark experimentation' (the image of the electric chair comes to mind) or the wide-eyed miracle phase? Have we ever 
dissociated ourselves from the early image of electricity - that invisible, supernatural given that requires no labour or resources to be made available to us?

This throws up further questions about the role that materiality and immateriality play in our relationship with electricity. Literary theorist Steven Connor (2004), for instance, argues that the first phase of electric imagination and experimentation is characterised by electricity as a sensory object, whereas the second phase of our interaction with it ('after Faraday') is more abstract, use-value orientated. This seems reflected in the transition from the sensory Generation to the more pragmatic Supply. From Connor's article one gets the impression that the 'immaterial' is associated with the future. By contrast, Wolfgang Schivelbusch suggests in his book, The Disenchanted Night (1988), that electrification might follow a more nonlinear pattern. Sometimes things discarded by 'progress' re-materialise: the lightbulb is, in some respects, more archaic than the gas lamp. Against the background of the 'invisibility' theme, I wondered whether today's simultaneous ubiquity and hiddenness of electricity present an obstacle or aid to our capacity to handle electricity in the future.

In this context, two things that could have been given more attention are consumption drivers and human development, which, for me, are actually connected. While there is an implicit questioning of consumption in some of the exhibits, the desire to increase it mostly appears to be taken for granted ('this is what people do'). One the one hand, this may prevent explicit moralising that could prevent an engagement by a wider audience, especially since this is designed as an international travelling exhibition. On the other hand, it would tie in with the more existential theme of the exhibition, of plumbing the past to generate future human pathways. In this theme, the energy-economy relation plays a strong role: how and by whom should electricity be managed? What does energy development mean, especially regarding global North-South relations? Further, if electricity ('the spark of life') makes us human, both physically and culturally, it is likely to continue to do so. What are potential human or, as some people call it, posthuman futures, as seem through the lens of electricity? After all, electricity seems to power an increasingly complex relationship between human and machine. How could electricity alter our brains, our ways of interacting, our relationship with our (natural, technological) environment (and beyond)? While the exhibition was clearly more focused on feeding into the debate on energy, exhibits throughout the show seemed to push for bolder imagination of human (or not so recognisably human) futures. Is carrying on business as usual, but with a more decentralised grid all we can come up with? Clearly, the history of electricity was shaped by often wacky ideas, some of which even proved useful in the long run. The present and future could perhaps do with some of these, too.

\section{(Post)human futures}

In her Cyborg Manifesto, Donna Haraway argues that cyborg imagery - the questioning of binaries such as the human and machinic- can function as an 
assertion of 'global vengeance' by showing how boundaries are constantly constructed and deconstructed. The tropes that keep women and nonheteronormative bodies, ethnic and religious groups, animals and machines in place need to be shown not just as to what they are - strategic power play - but also in their fragility, as attackable formations. The two Wellcome exhibitions could be seen as attempts to support this revolutionary project, as they both stress the lack of clear separations. While the destabilisations are palpable, the force of 'global vengeance' is not so much. I am proposing two reasons: either, the vertigo is not pushed far enough, or the 'global vengeance' has to be imagined less as a fiery sweep than as a more quiet subterfuge that even makes it into mainstream institutions.

Regarding the latter, recent examples of natural entities such as rivers, forests and animals being granted legal 'personhood' status appear to affirm a gradual shift of the dominant worldview, although whether on a deeper or cosmetic scale remains to be debated. At the same time, this institutionally acceptable shift feels too safe, not really constituting an obstacle to on-going harmful practices. People can be harmed without significant consequences (war, environmental racism, police violence, withdrawal of women's health and domestic violence services), so rivers are likely to end up in the same position. Will a profound destabilisation ever be allowed as long as too many people continue to profit from the old divisions? How much can environmental constraints and threats - to come back to the Anthropocene theme - force a potential shift, and, if such as shift occurs, will it be for the worse of much of humanity? These are questions that were implicit rather than explicit in both exhibitions. Part of me wishes these questions to be made more explicit - like a much needed scream in the face of impending disaster - and another part of me feels that this might be counter-productive, as it also vocalises a feeling of powerlessness.

What especially the Electricity exhibition did well was to give hands-on information at the end, leaving visitors with a sense of what is possible. While this may constitute a limitation through its relatively narrow focus, this practice could be expanded to show the range of options that people have if they wanted to continue boundary destabilisations on a larger scale. What exhibition visitors might want to know is not necessarily just what kinds of energy or animal futures there might be but how to work towards a shift of the underlying worldview, whether it is by spreading a new language or by joining or supporting pressure groups. After all, it seems impossible for benevolent energy futures and co-habitation with other species to occur without a wider shift in attitude towards the planet, including other people. What examples are there, for example, from indigenous movements who are still fighting to shake off violent colonial divisions? What examples are there from underground hacker spaces? If such examples keep getting exposure, perhaps there is a very different future for these conflicted upright bipeds, formed by sun and electricity. 


\section{References}

Allora \& Calzadilla \& Ted Chiang (2015) The Great Silence. E-Flux. Available at: http://supercommunity.e-flux.com/texts/the-great-silence/ (accessed 10 April 2017)

Connor, S (2004) 'Volts from the Blue'

http://stevenconnor.com/volts.html (accessed 11 April 2017)

Gleiser, M (2017) Is Neuroscience Rediscovering The Soul? 13.7 Cosmos \& Culture (NPR). 5 April 2017.

http://www.npr.org/sections/13.7/2017/04/05/522738015/is-neurosciencerediscovering-the-soul (accessed 12 April 2017)

Glissant, E (1958) La Lézarde. Paris: Editions du Seuil.

Haraway, D J (1991) Simians, Cyborgs and Women: The Reinvention of Nature. London: Routledge.

Nadim, T, Sonjasdotter, Å (2015) Dead Wasps Fly Further/Tote Wespen Fliegen Länger. Museum für Naturkunde Berlin. 3 March - 3 May 2015.

https://www.naturkundemuseum.berlin/en/museum/exhibitions/dead-wasps-flyfurther (accessed 10 April 2017)

Schivelbusch, W (1988) The Disenchanted Night. Berkeley: University of California Press.

The Prestige. 2006. Christopher Nolan. Buena Vista Pictures/Warner Bros. 